\title{
Anesthetized Lethal Injection Exsanguination Euthanasia
}

National Cancer Institute

\section{Source}

National Cancer Institute. Anesthetized Lethal Injection Exsanguination Euthanasia. NCI

Thesaurus. Code C116221.

A method of euthanasia whereby a subject is anesthetized, a lethal chemical is administered by injection and the body is drained of blood. 